\title{
Trypanosoma cruzi
}

National Cancer Institute

\section{Source}

National Cancer Institute. Irypanosoma cruzi. NCI Thesaurus. Code C125977.

A species of parasitic eug lenoid protozoan in the family Trypanosomatidae. T. cruzi is passed between mammalian hosts through the feces of a triatomine insect vector. Infection in humans causes Chagas disease. 